Check for updates

Cite this: RSC Adv., 2019, 9, 30052

Received 15th August 2019

Accepted 16th September 2019

DOI: $10.1039 /$ c9ra06392g

rsc.li/rsc-advances

\section{High effectiveness of pure polydopamine in extraction of uranium and plutonium from groundwater and seawater $\uparrow$}

\author{
Valery N. Bliznyuk, (D) *ae Kamila Kołacińska, (D) ${ }^{\text {b }}$ Alexander A. Pud, (D) ${ }^{c}$ \\ Nikolay A. Ogurtsov, (D) C Yuriy V. Noskov, (D) B Brian A. Powell (iD ade \\ and Timothy A. DeVol*ae
}

Sorption properties of polydopamine (PDA) for uranium and plutonium from an aqueous environment are reported at three different $\mathrm{pH}$ values (2, 4 and 6.5-7). In addition to deionized (DI) water, artificial groundwater (GW) and seawater (SW) were used with $U$ uptake close to $100 \%$ in each case. PDA polymer has been identified as a material with extremely high sorption capacity $Q_{\max } \sim 500 \mathrm{mg} \mathrm{g}^{-1}$ of the polymer at $\mathrm{pH} 6.5$ and high selectivity for uranium. Similar high sorption properties are revealed for plutonium uptake. PDA-uranyl and PDA-plutonium interactions responsible for the observed adsorption processes have been addressed with a set of experimental techniques including FTIR spectroscopy, electron microscopy and cyclic voltammetry.

\section{Introduction}

Since the first few references on polydopamine (PDA) in 1970-2006 (ref. 1-4) and an encouraging paper on musselinspired multifunctional PDA coatings in $2007,{ }^{5}$ interest in this polymer has grown significantly due to a rapidly expanding range of potential applications of PDA and its composites in energy storage, catalysis, filtration, biomedical systems (sensors, drug delivery, theranostics), environmental cleaning and heavy metal accumulation, etc. ${ }^{6-8}$ PDA potentialities stem from its fascinating combination of catecholamine with other functionalities and, paradoxically, from a diverse, not quite understood yet supramolecular organization and composition. These two major factors hopefully promise the bright future and applications of this polymer. In fact, the uncertainty of the PDA qualitative and quantitative composition is predetermined by both the

\footnotetext{
${ }^{a}$ Department of Environmental Engineering and Earth Sciences, Clemson University, Clemson, SC 29634-0919, USA.E-mail:vblizny@clemson.edu; devol@clemson.edu

${ }^{b}$ Institute of Nuclear Chemistry and Technology in Warsaw, Poland

${ }^{c} V$. P. Kukhar Institute of Bioorganic Chemistry and Petrochemistry, NAS of Ukraine, 50 Kharkivske Shose, Kyiv 02160, Ukraine

${ }^{d}$ Department of Chemistry, Clemson University, Clemson, SC 29634, USA

${ }^{e}$ Nuclear Environmental Engineering Sciences and Radioactive Waste Management (NEESRWM) Center, Clemson University, Clemson, SC 29634-0942, USA

$\uparrow$ Electronic supplementary information (ESI) available: The ESI file contains additional figures showing variation of the PDA structure under different $\mathrm{pH}$ (FTIR spectra), analysis of uranium sorption from seawater (kinetics and adsorption isotherm fits with different models), morphology of pure PDA from STEM, and EDX spectra confirming accumulation of $U$ and Pu elements in the PDA matrix from aqueous environments. See DOI: 10.1039/c9ra06392g
}

diversity of insoluble or poorly soluble products of dopamine oxidation/polymerization (the covalently bound polymer, oligomers and noncovalent stacked (dopamine) ${ }_{2} / 5,6$ dihydroxyindole (DHI) trimers) and their ability to selforganize due to intermolecular interactions (H-bonding, van der Waals, $\pi-\pi$ and charge transfer interactions, etc.) (Fig. 1). ${ }^{9,10}$

In turn, this diversity fits well with some applications that need a wide set of functional groups facilitating PDA ability for chemical transformation/tailoring ${ }^{8,11,12}$ as well as in removal of organic compounds or removal/accumulation of heavy metals/radionuclides from aqueous media., ${ }^{73-16}$ Among currently known PDA applications, the environmental field can be considered as extremely important because of an inevitable release of pollutants from industry, nuclear stations and waste disposal facilities, as well as of a possible recovery of radioactive elements from natural sources in GW and SW. Initially, such PDA applicability was suggested on the basis of the above-mentioned mussel-like functionalities, which are prone to form adhesion bonds with different surfaces through noncovalent metal coordination or chelating, hydrogen bonding, $\pi-\pi$ stacking, cation- $\pi$ interactions and quinhydrone charge-transfer complexes. ${ }^{6,7,17}$ Naturally, due to the similar interactions and the rich surface chemistry, the insoluble PDA can quite effectively adsorb/absorb many pollutants. While only few papers demonstrate the applicability of pure PDA for the heavy metal removal, ${ }^{\mathbf{1 6}, 18}$ in most cases it is used in a form of its (nano)composites to get high surface contacts with solutions of the pollutants and probably synergistic enhancement of the absorption - as compared with the pure 


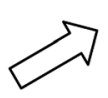<smiles>NCCC1=CC(=O)C(=O)C=C1</smiles>

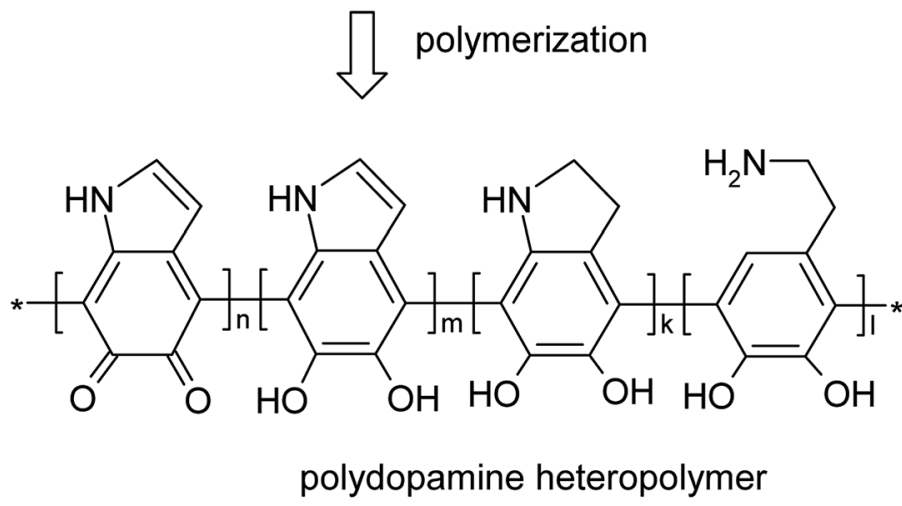<smiles>[Z]c1cc2cc(O)c(O)c(-c3cc4c([Z])c(O)c(O)c([Z])c4[nH]3)c2[nH]1</smiles><smiles>Cc1cc2c([nH]1)=CC(=O)C(=O)C=2</smiles>

5,6-indolequinone

melanine-like oligoindole

Fig. 1 Alternative structures of PDA with covalent versus hydrogen bond self-assembly structures. ${ }^{5-9}$

PDA. , $7,13-15,19,20$ Quite impressive results in the nanocomposites case have been demonstrated, especially when it comes for removal of some radionuclides (e.g. uranium and plutonium) from water media. In particular, for the nanocomposites of $\mathrm{mSiO}_{2} / \mathrm{PDA}$ and waste paper derived carbon coated with PDA (WPC@PDA) the calculated maximum capacities for uranium $\mathrm{U}(\mathrm{vI})$ were $332.3 \mathrm{mg} \mathrm{g}^{-1}$ at $T=318.5$ $\mathrm{K}, \mathrm{pH}=5.5\left(287.5 \mathrm{mg} \mathrm{g}^{-1} \text { at } T=298.15, \mathrm{pH}=5.5\right)^{21}$ and $384.6 \mathrm{mg} \mathrm{g}^{-1}$ at $T=298 \mathrm{~K}, \mathrm{pH}=7.0,{ }^{22}$ respectively. The only (to the best of our knowledge) comparison of a PDA nanocomposite and pure PDA was made by Zhu et al. at lower $\mathrm{pH}$ $=4.5$ and $T=298 \mathrm{~K}^{15}$ They calculated that the adsorption capacities of the core-shell polydopamine@MgAl-layered double hydroxide (PDA@MgAl-LDH) and pure PDA were $142.86 \mathrm{mg} \mathrm{g}^{-1}$ and $54.05 \mathrm{mg} \mathrm{g}^{-1}$, respectively. ${ }^{15}$ This paper confirmed the importance of high surface area and possible synergy of the different components of the nanocomposite for the effective pollutants' removal. ${ }^{15}$ Nevertheless, keeping in mind the significance of these factors, we have to remember that a substantial part of the PDA functional groups (amine or catechol) in the composite shells are involved in formation of adhesion bonds with the surface of the other component and, therefore, cannot interact with the pollutant ions/molecules. In the case of core-shell nanocomposites this adhesion effect can be decreased due to increasing the PDA shell thicknesses that supplies more binding sites for the actinide adsorption..$^{23}$ Therefore, to find the best effective absorbing material we have to determine an optimal ratio of the components in a PDA based (nano)composite. To realize this, we need to know more about a pure PDA binding ability. ${ }^{15}$ In this communication we report on properties of PDA as a sorbent for actinides (U and $\mathrm{Pu}$ ) under laboratory and real-life environmental conditions of GW and SW.

\section{Experimental section}

\subsection{Synthesis of polydopamine}

PDA was synthesized through the self-polymerization of dopamine in tris(hydroxymethyl)aminomethane (Tris)- $\mathrm{HCl}$ buffer $(20 \mathrm{mM}, \mathrm{pH} \sim 8.5)$ as described elsewhere. ${ }^{5}$ In short, dopamine hydrochloride ( $0.3 \mathrm{~g}$, Acros) was dissolved in $60 \mathrm{~mL}$ of distilled water. Then previously prepared $3 \mathrm{M}$ Tris$\mathrm{HCl}$ water solution $(0.4 \mathrm{~mL})$ was added to this dopamine solution. The reaction mixture was stirred for 4 days. The final dark-brown dispersion was then purified by dialysis through a tubing cellulose membrane (D9777, MWCO = 14000 ) for $72 \mathrm{~h}$ against distilled water. Then PDA was separated from the dispersion by centrifugation at $3000 \mathrm{rpm}$ for $15 \mathrm{~min}$ followed by drying at ambient conditions for $48 \mathrm{~h}$ and then in dynamic vacuum for $3 \mathrm{~h}$. The resulting yield of PDA was around $20 \%$.

\subsection{Preparation of the actinide solutions}

Sorption properties of PDA for uranium and plutonium were studied at three different $\mathrm{pH} 2,4$ and 6.5-7.

Uranium working solution preparation. Uranyl nitrate hexahydrate $\left(\mathrm{UO}_{2}\left(\mathrm{NO}_{3}\right)_{2} \cdot 6 \mathrm{H}_{2} \mathrm{O}\right)$ was obtained from 
International Bioanalytical Industries, Inc. (Boca Raton, FL) typically dissolved in DI water to create a concentration of 100 or 200 ppm total uranium then spiked with ${ }^{233} \mathrm{U}$ to have $\sim 10 \mathrm{~Bq}$ $\mathrm{ml}^{-1}$ activity. The ${ }^{233} \mathrm{U}$ was obtained from Eckert and Ziegler Isotope Products (Valencia, CA). Whereas this prepared solution was initially slightly acidic, its desirable level of $\mathrm{pH}$ (2, 4 and 6.5-7) was adjusted with addition of $\mathrm{HNO}_{3}$ or $\mathrm{NaOH}$. To achieve a reasonable level of solubility of uranium under neutral condition ( $\mathrm{pH}=6.5)$, mineral water "Muszynianka" (Poland) with high content of bicarbonate (1477 ppm) and some other elements: $\left(\mathrm{Mg}^{2+} 132 \mathrm{ppm} ; \mathrm{Ca}^{2+} 220 \mathrm{ppm} ; \mathrm{Na}^{+} 59 \mathrm{ppm} ; \mathrm{K}^{+}\right.$ $\left.6.5 \mathrm{ppm} ; \mathrm{SO}_{4}{ }^{2-} 26 \mathrm{ppm} ; \mathrm{Cl}^{-} 8.9 \mathrm{ppm}\right)$ was used instead of DI water.

For GW extraction experiments, an artificial GW solution was prepared in accordance to the composition described elsewhere. ${ }^{23}$ To achieve required concentrations of ions, $1 \mathrm{~L}$ of GW was prepared by 7.5 times dilution of mineral water "Muszynianka" (Poland) followed by addition of salts: $\mathrm{NaF}$ (20 mg), $\mathrm{Na}_{2} \mathrm{SO}_{4}(6 \mathrm{mg}), \mathrm{KCl}(9 \mathrm{mg}),\left(\mathrm{NH}_{4}\right) \mathrm{Cl}(11 \mathrm{mg}),\left(\mathrm{NH}_{4}\right)$ $\mathrm{NO}_{3}(8 \mathrm{mg})$. The $\mathrm{pH}$ was adjusted with $\mathrm{NH}_{3}$ up to 7.02. Ion concentrations were controlled by ion-chromatography and confirmed the desired composition of the GW solution. In the last step, GW was spiked with $10 \mathrm{mg}$ of natural uranium (taken from a standard solution of $\mathrm{U}\left(2 \mathrm{~g} \mathrm{~L}^{-1}\right)$ in nitric acid). The addition of uranium increased to some extent the concentration of nitrates above the typical value. The $\mathrm{pH}$ value was re-adjusted with $\mathrm{NH}_{3}$ up to 7.05. The GW was left for $48 \mathrm{~h}$ for stabilization.

Uranium-spiked SW (described in literature) ${ }^{24}$ was prepared by dissolving $35.1 \mathrm{~g}$ of Instant Ocean Salt ${ }^{25}$ in $1 \mathrm{~L}$ of DDI water. Uranium solution of $1 \mathrm{~Bq} \mathrm{~mL}{ }^{-1}$ concentration was prepared by adding $0.43 \mathrm{~mL}$ of uranium-233 of $500 \mathrm{~Bq} \mathrm{~mL}{ }^{-1}$ concentration in $215 \mathrm{~mL}$ of sea water $\left(50 \mu \mathrm{g} \mathrm{L}^{-1}\right)$. The $\mathrm{pH}$ of the solution was neutral.

Plutonium working solution preparation. A ${ }^{239} \mathrm{Pu}(\mathrm{vI})$ aqueous stock solution was prepared by dissolving a small amount of suspended ${ }^{239} \mathrm{PuO}_{2}$ particles (obtained from Oak Ridge National Laboratory (ORNL)) in $8 \mathrm{M} \mathrm{HNO}_{3} / 0.01 \mathrm{M} \mathrm{HF}$ solution. The resulting solution was evaporated to dryness in a Teflon vessel by passing dry air through the vessel held at $50{ }^{\circ} \mathrm{C}$. The residue was dissolved in $2 \mathrm{~mL}$ of $5 \mathrm{M} \mathrm{HClO}_{4}$ and heated at approximately $80{ }^{\circ} \mathrm{C}$ on a hotplate. Dry air was passed through the sample headspace during heating and captured in a $1 \mathrm{M} \mathrm{KOH}$ solution to avoid release of perchloric acid vapors. The solution was heated for 24 hours after which a slight pink color appeared then diluted to a $0.5 \mathrm{mM}{ }^{239} \mathrm{Pu}$ solution with a residual perchlorate concentration of approximately $10 \mathrm{mM} \quad \mathrm{HClO}_{4}$. The concentration of ${ }^{239} \mathrm{Pu}$ in solution was determined by liquid scintillation counting and correcting for the isotopic abundance of other $\mathrm{Pu}$ isotopes as reported by ORNL. The solution was found to be $>95 \% \mathrm{Pu}(\mathrm{VI})$ using UV-Vis spectroscopy and $\mathrm{LaF}_{3}$ co-precipitation. The dominant $\mathrm{Pu}(\mathrm{vI})$ bearing species in this $10 \mathrm{mM} \mathrm{HClO}_{4}$ solution are the dioxycations $\mathrm{PuO}_{2}{ }^{2+}$.

To measure uptake of plutonium at different $\mathrm{pH}$ values, its solutions were diluted from a $6.0 \times 10^{5} \mathrm{~Bq} \mathrm{~mL}^{-1}$ stock solution in $8 \mathrm{M} \mathrm{HNO}_{3}$ from the Clemson University Environmental Radiochemistry Laboratory inventory. The plutonium was originally purchased as $\mathrm{PuO}_{2}(\mathrm{~s})$ from ORNL and a $10 \mathrm{mg}$ aliquot dissolved in $\mathrm{HNO}_{3} / \mathrm{HF}$ with heating. The resulting solution was evaporated to dryness and reconstituted in $8 \mathrm{M} \mathrm{HNO}_{3}$ for purification on a TEVA resin column. The $\mathrm{Pu}$ solution was loaded from $8 \mathrm{M} \mathrm{HNO}_{3}$ and eluted in a mixture of $1 \mathrm{M} \mathrm{HCl}$ and 0.25 M HF. The elution was evaporated to incipient dryness. Small aliquots $(0.5 \mathrm{~mL})$ of $8 \mathrm{M} \mathrm{HNO}_{3}$ were added and evaporated to remove trace chloride and fluoride then the final solution was reconstituted in approximately $40 \mathrm{~mL}$ of $8 \mathrm{M}$ $\mathrm{HNO}_{3}$. Determination of the oxidation state of the stock solution using solvent extraction indicated 92\% $\mathrm{Pu}(\mathrm{Iv}), 5 \% \mathrm{Pu}(\mathrm{v})$, and $3 \% \mathrm{Pu}(\mathrm{vI})$. To prepare experimental working solutions, the stock solution was diluted to $25 \mathrm{~Bq} \mathrm{~mL}^{-1}\left(7.02 \times 10^{-7} \mathrm{M}\right)$ and adjusted to the desired $\mathrm{pH}$ with small volumes of $\mathrm{HCl}$ and $\mathrm{NH}_{4} \mathrm{OH}$ solutions.

\subsection{Adsorption experiments}

In a typical sorption experiment $50 \mathrm{~mL}$ polypropylene centrifuge tube was loaded with $20 \mathrm{mg}$ of dry PDA powder and $10 \mathrm{~mL}$ of the aqueous actinide solution and was then shaken on a rotor for at least $48 \mathrm{~h}$. After centrifuging at $6000 \mathrm{rpm}$ for $15 \mathrm{~min}, 5 \mathrm{~mL}$ top fraction (in some experiments $1 \mathrm{~mL}$ ) was taken out and replaced with $5 \mathrm{~mL}$ of the fresh $\mathrm{UO}_{2}\left(\mathrm{NO}_{3}\right)_{2}$ solution of the original concentration. The extracted $5 \mathrm{ml}$ (or 1 $\mathrm{mL}$ ) solution was used for analysis and the remaining main portion with the PDA sample was put for the next $48 \mathrm{~h}$ extraction (with continuous mixing). A $1 \mathrm{~mL}$ top portion of the $5 \mathrm{~mL}$ eluent was filtered through $0.45 \mu \mathrm{m}$ Teflon syringe filter (to remove dispersed particles of PDA) and added to $20 \mathrm{~mL}$ borosilicate glass scintillation vials with $10 \mathrm{~mL}$ of Ultima Gold $^{\mathrm{TM}} \mathrm{AB}$ scintillation cocktail and counted on a PerkinElmer 1220 Quantulus ultra low-level liquid scintillation spectrometer for 15 or 90 minutes (depending on the activity of the initial solution). Comparison of the count rate for eluent after adsorption with that of the original stock solution (reference sample) provided the amount of the radionuclide adsorbed by PDA. The whole procedure was repeated until saturation on the dependence of accumulated radionuclide versus mixing step has been observed.

In the case of plutonium, we could not work with high concentration solutions and measured retention of ${ }^{242} \mathrm{Pu}$ from $25 \mathrm{~Bq} \mathrm{~mL} \mathrm{~m}^{-1}$ activity solutions (170 ppb) in a single step experiment.

The GW extraction experiments were run by a little different protocol and only in a single step experiment. Specifically, approximately $20 \mathrm{mg}$ of PDA was mixed with $40 \mathrm{~mL}$ of GW solution and shaken for $48 \mathrm{~h}$ on the rotor. After this time, the sample was centrifuged (20 min, $6000 \mathrm{rpm}$ ) and filtered with standard syringe filter $(0.45 \mu \mathrm{m})$. A blank sample taken to the experiment was only GW solution without any sorbent. Filtrates were directly measured by ion chromatography. For ICP-MS detection of ${ }^{238} \mathrm{U}$ and $\mathrm{Si}$, filtrates were diluted 66 times $(0.15 \mathrm{~mL}$ to $10 \mathrm{~mL})$. The $\mathrm{pH}$ values were measured before and after sorption experiment. 


\subsection{Characterization}

Electron microscopy measurements in scanning transmission electron microscopy (STEM) mode and the elemental analysis of the PDA sample with the absorbed radionuclides energy dispersion spectroscopy-(EDS) were performed with the help of Hitachi HD-2000 microscope, $20 \mathrm{kV}$ accelerating voltage. To realize these measurements PDA sample with pre-adsorbed uranium (280 $\mathrm{mg}{ }^{238} \mathrm{U}$ per $1 \mathrm{~g}$ of polymer) from sorption capacity test and specially prepared PDA with pre-adsorbed plutonium (65 $\mu \mathrm{g}{ }^{239} \mathrm{Pu}$ per $1 \mathrm{mg}$ of polymer) were used for sample preparation. After sorption from $0.0125 \mathrm{mM}\left({ }^{239} \mathrm{Pu}\right.$; $6890 \mathrm{~Bq} \mathrm{~mL} \mathrm{~mL}^{-1}$ ) concentration solution for one week some amount of PDA precipitate was transferred in a separate vial, dispersed in water and then deposited on copper grids covered with carbon films.

Fourier transform infra-red spectra in attenuated total reflection mode (ATR-FTIR) of PDA samples without and with the absorbed radionuclides were obtained with the help of Thermo Scientific 6700 spectrometer equipped with a mercury cadmium telluride narrow band detector and Smart iTR single bounce diamond ATR crystal.

Cyclic voltammetry (CV) studies were performed via a WaveDriver 20 Bipotentiostat/Galvanostat using a BASi VC-2 voltammetry cell $(20 \mathrm{~mL})$, working glassy carbon (bare and coated with the samples with and without radionuclides), Pt counter and $\mathrm{Ag} / \mathrm{AgCl}$ reference electrodes, correspondingly. In short, $\mathrm{CV}$ measurements were performed as follows: a pre-cleaned glassy carbon (BASi MF-2012) electrode $(d=3.0 \mathrm{~mm})$ was put in a vertical position, small amount of PDA $(\sim 20 \mu \mathrm{g})$ with pre-adsorbed ${ }^{238} \mathrm{U}(6 \mu \mathrm{g})$, or ${ }^{239} \mathrm{Pu}(\sim 0.8 \mu \mathrm{g})$ was deposited on its clean horizontal surface from water dispersion and the electrode was left for drying for one day. Such preparation procedure insured good adhesion and electrical contact between the PDA film and glassy carbon electrode surface. Typically, 6-7 mL of electrolyte (water with $[\mathrm{Na}]\left[\mathrm{ClO}_{4}\right]$ or acetonitrile with $\left[\mathrm{Bu}_{4} \mathrm{~N}\right]\left[\mathrm{PF}_{6}\right]$ supporting electrolytes in $0.1 \mathrm{M}$ concentration) were used in $20 \mathrm{~mL}$ glass vial under argon. The cyclic voltammograms were scanned in the potential windows from -0.6 to $+1.2 \mathrm{~V}$ (water-based electrolyte) and from $-1.8 \mathrm{~V}$ to $+1.8 \mathrm{~V}$ (acetonitrile-based electrolyte) at sweeping rate $50 \mathrm{mV} \mathrm{s}^{-1}$ with 5 scans for each scan rate after conditioning for $2 \mathrm{~h}$ with $100 \mathrm{mV} \mathrm{s}^{-1}$ potential scanning. The acetonitrile-based electrolyte was used to visualize at high potentials redox processes of $\mathrm{Pu}$ adsorbed by PDA.

\section{Results and discussion}

\subsection{The actinide moieties uptake from the model aqueous} solutions

The applied sorption method of the uptake measurements involves simultaneously changes in two parameters (radionuclides concentration and time) of the system and gives the direct measurement of the maximum sorption capacity $\left(Q_{\max }\right)$. Specifically, in this method $Q_{\max }$ is not a result of a typical mathematical extrapolation of values measured from a low concentration to a high concentration but represents a real

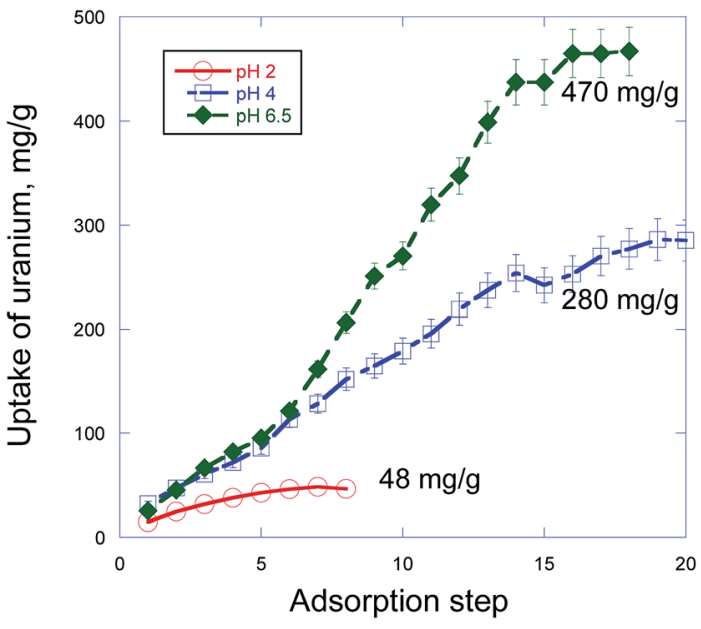

Fig. 2 Uranium sorption capacity test by PDA from aqueous solutions via step-by-step accumulation at three different $\mathrm{pH}$ values.

experimental fact of saturation of the uptake process after several steps of the radionuclide sorption with the same portion of the sorbent (PDA). In particular, we have found that pure PDA has really strong ability to absorb significant amount of actinides, which however strongly depends on $\mathrm{pH}$ of the solution. Thus, as one can see from Fig. 2 and Table 1, $Q_{\max }$ values for uranium and retention for plutonium sharply increase from $\mathrm{pH}$ 2 to $\mathrm{pH} 4$ and then at $\mathrm{pH}$ 6-6.5 quite strongly grow in the former and very weakly grow for the latter. This tendency is well illustrated in Fig. 2 showing strong dependence of the development of the uranium uptake on $\mathrm{pH}$, which in turn is predetermined by $\mathrm{HNO}_{3}$ concentration.

Dependence of the radionuclides sorption on $\mathrm{pH}$ both for PDA containing core-shell composites ${ }^{15,21,22,26}$ and other materials ${ }^{27-29}$ is well known and is typically assigned to change of charge state of both the radionuclide bearing species and the sorbent surface. In particular, the main U(vI) species in aqueous solution were predominated by $\mathrm{UO}_{2}{ }^{2+}$ cations at $\mathrm{pH}<4$. At higher $\mathrm{pH}$ around 5-8 the mixture of complex cations $\mathrm{UO}_{2}(\mathrm{OH})^{+}, \quad\left(\mathrm{UO}_{2}\right)_{3}(\mathrm{OH})^{5+}$ and $\left(\mathrm{UO}_{2}\right)_{4}(\mathrm{OH})^{7+}$ and neutral $\mathrm{UO}_{2}(\mathrm{OH})_{2}$ species prevail. ${ }^{15,21}$ Importantly that in our case due to high carbonate content (200 ppm to $2 \mathrm{mM} \mathrm{Na}_{2} \mathrm{CO}_{3}$, see Experimental methods) at $\mathrm{pH} 6.5$ in the solution there present $\mathrm{UO}_{2} \mathrm{CO}_{3}(\mathrm{aq})$ and $\left[\mathrm{UO}_{2}\left(\mathrm{CO}_{3}\right)_{2}\right]^{2-}$ species, which obviously also effect $\mathrm{U}(\mathrm{vI})$ adsorption on PDA. ${ }^{30}$

Inevitably, in the case of core-shell particulate sorbents with a PDA shell and of pure PDA, the adsorption of the radionuclide species will be affected by the sorbent surface charge. Indeed, it was demonstrated that at $\mathrm{pH}$ higher than $\sim 3.7$ the $\zeta$-potential of the surface of $\mathrm{Fe}_{3} \mathrm{O}_{4}$ @PDA nanoparticles was negative that facilitated adsorption of the complex uranyl hydrated cations. ${ }^{26}$ At lower $\mathrm{pH}$ the surface charge was positive that suppressed adsorption of $\mathrm{UO}_{2}{ }^{2+}$ cations ${ }^{26}$ and, obviously, of $\mathrm{PuO}_{2}{ }^{2+}$ cations.

At first view these physico-chemical differences in all participants of the sorption processes in the PDA based system can explain dependence of the radionuclides 
Table 1 Experimental conditions and detection techniques applied for uranium and plutonium uptake measurements under various environments

\begin{tabular}{|c|c|c|c|c|c|c|}
\hline \multirow[t]{2}{*}{${ }^{238} \mathrm{U} /{ }^{233} \mathrm{U}$} & 2 & $100 \mathrm{ppm}$ & $10 \mathrm{~Bq} \mathrm{~mL}^{-1}$ & DI water with $\mathrm{HNO}_{3}$ & $\operatorname{LSC}^{a}$ & 70 \\
\hline & 6.5 & $100 \mathrm{ppm}$ or $200 \mathrm{ppm}$ & $\begin{array}{l}1.24 \mathrm{~Bq} \mathrm{~mL}^{-1} \\
2.5 \mathrm{~Bq} \mathrm{~mL}^{-1}\end{array}$ & Mineral water & ${\mathrm{ICP}-\mathrm{MS}^{b}}^{b}$ & 100 \\
\hline${ }^{242} \mathrm{Pu}$ or ${ }^{239} \mathrm{Pu}$ & 2 & $170 \mathrm{ppb}$ & $25 \mathrm{~Bq} \mathrm{~mL}^{-1}$ & DI water with $\mathrm{HNO}_{3}$ & LSC and ICP-MS & 60 \\
\hline${ }^{238} \mathrm{U}$ & 7 & $10.4 \mathrm{ppm}$ & $0.124 \mathrm{~Bq} \mathrm{~mL}^{-1}$ & Spiked GW & ICP-MS & 100 \\
\hline${ }^{233} \mathrm{U}$ & 7 & $40 \mathrm{ppb}$ & $1.3 \mathrm{~Bq} \mathrm{~mL}^{-1}$ & Spiked SW & LSC & 100 \\
\hline${ }^{233} \mathrm{U}$ & 7 & $130 \mathrm{ppb}$ & $45.9 \mathrm{~Bq} \mathrm{~mL}^{-1}$ & Spiked SW & LSC & 100 \\
\hline
\end{tabular}

maximum sorption capacity $\left(Q_{\max }\right)$ or retention on $\mathrm{pH}$ (Table 1). However, despite the differences, the sorption processes at $\mathrm{pH} 4$ and 6.5 proceed similarly with a very close $\mathrm{U}(\mathrm{vI})$ uptake rates up to $6^{\text {th }}$ step $(336 \mathrm{~h}$ ) (Fig. 2) under investigation. This result strongly differs from the known fact that adsorption of $\mathrm{U}(\mathrm{vI})$ at PDA hybrid core-shell nanocomposites is much higher at $\mathrm{pH}>5$ than that of at $\mathrm{pH}$ $4 .^{15,21,22,26}$ In particular, in accord with Fig. 2 in ref. $26 \mathrm{U}(\mathrm{vI})$ adsorption efficiency at core-shell $\mathrm{Fe}_{3} \mathrm{O}_{4} @ P D A$ nanocomposite for $200 \mathrm{~h}$ sharply increased (about triplicated) when transition from $\mathrm{pH} 4$ to $\mathrm{pH}$ 6. The found proximity of the $\mathrm{U}(\mathrm{vI})$ adsorption behavior at $\mathrm{pH} 4$ and 6.5 up to $6^{\text {th }}$ step (Fig. 2) suggests independence of a quantity and origin of binding sites in PDA (at these $\mathrm{pH}$ ) and a similar kinetics of their interaction with existing in the solutions different $\mathrm{U}(\mathrm{vI})$ species. However, after these steps the $\mathrm{U}(\mathrm{vI})$ sorption at $\mathrm{pH}$ 6.5 accelerates about twice (can be estimated from slopes of the curves) compared with that of at $\mathrm{pH} 4$ with the next linear uptake growth up to $14^{\text {th }}$ step followed by tendency to saturation (Fig. 2). Reasons of this significant change in the interaction rate at $\mathrm{pH} 6.5$ are not clear yet completely and need to be studied separately. Nevertheless, taking into account the fact that under investigation at $\mathrm{pH} 6.5$ there coexist different $\mathrm{U}(\mathrm{vI})$ neutral or charged species bearing one or few uranium atoms $\left[\mathrm{UO}_{2}(\mathrm{OH})^{+}, \quad\left(\mathrm{UO}_{2}\right)_{3}(\mathrm{OH})^{5+}\right.$, $\left.\left(\mathrm{UO}_{2}\right)_{4}(\mathrm{OH})^{7+}, \mathrm{UO}_{2}(\mathrm{OH})_{2}, \mathrm{UO}_{2} \mathrm{CO}_{3}(\mathrm{aq}),\left[\mathrm{UO}_{2}\left(\mathrm{CO}_{3}\right)_{2}\right]^{2-}\right],,^{15,21,30}$ as one of possible explanations we suggest different kinetics of adsorption of these species at negatively charged surface of PDA. Obviously, smaller species with one uranium atom are more movable and can diffuse/adsorb to/at the PDA surface faster than larger ones with more quantity of uranium atoms that gives slower $\mathrm{U}(\mathrm{vI})$ uptake rate in the former case. After subsequent decrease of the concentration of smaller species in the solution (even despite addition of small portion of the fresh $\mathrm{U}(\mathrm{vI})$ solution under investigation) the heavier species begin to prevail in the $\mathrm{U}(\mathrm{vI})$ uptake. This leads to a formal increase of the uptake rate (but just for account of the heavier species) which is revealed in the slope of the sorption curve at $\mathrm{pH} 6.5$ after $6^{\text {th }}$ step in Fig. 2. This explanation matches well with the practically similar $\mathrm{U}(\mathrm{vI})$ uptake at $\mathrm{pH} 4$ up to $6^{\text {th }}$ step for account obviously of adsorption of prevailing in this medium $\mathrm{UO}_{2}{ }^{2+}$ species bearing only one uranium atom and with invariability of the uptake rate with actually linear uptake $\mathrm{U}(\mathrm{vI})$ growth up to $14^{\text {th }}$ step followed by tendency to saturation.

While in the case of plutonium such sorption measurements were not performed, we found that its retention from the low concentrated solutions also was higher at $\mathrm{pH} \geq 4$ (up to $100 \%$ ) and drops at lower $\mathrm{pH}(60 \%$ at $\mathrm{pH}$ 2) (Table 1, column 7 ).

From our view the low uptake of $U$ and Pu bearing species at $\mathrm{pH} 2$ can be caused not only by positive charge of PDA surface at this $\mathrm{pH}^{26}$ but probably also with oxidizing action of $0.01 \mathrm{M}$ $\mathrm{HNO}_{3}$ on PDA. This suggestion is supported by FTIR spectra of PDA powders after treatment in $\mathrm{HNO}_{3}$ solutions at $\mathrm{pH} \mathrm{2,} 4$ and 6.5 for 16 days (Fig. S1†). In particular, the PDA bands encompassing catechol O-H stretching vibrations at about $3214 \mathrm{~cm}^{-1}$ and $1286 \mathrm{~cm}^{-1}$ display a weak but quite clear irregular trend to decrease with increasing $\mathrm{HNO}_{3}$ concentration as compared with pristine PDA. This change matches well with a small simultaneous increase of the pronounced shoulder at $1720 \mathrm{~cm}^{-1}$, which encompasses carbonyl bands of both carboxylic groups and quinone units (see FTIR discussion below). All changes suggest

Table 2 Sorption of $U$ and some ions from artificial $\mathrm{GW}$ at $\mathrm{pH} 7.1$

\begin{tabular}{lll}
\hline $\begin{array}{l}\text { Ion (major species } \\
\text { at } \mathrm{pH} \text { 7.1 reported) }\end{array}$ & $\begin{array}{l}\text { Concentration } \\
{[\mathrm{ppm}]}\end{array}$ & Uptake\% \\
\hline $\mathrm{HCO}_{3}{ }^{-}$ & 200 & N/A \\
$\mathrm{F}^{-}$ & 8.8 & 5 \\
$\mathrm{Cl}^{-}$ & 18.1 & 0 \\
$\mathrm{NO}_{3}{ }^{-}$ & 129.8 & 0 \\
$\mathrm{SO}_{4}{ }^{2-}$ & 8.2 & 0 \\
$\mathrm{Na}^{+}$ & 21.3 & 0 \\
$\mathrm{~K}^{+}$ & 9.8 & 6 \\
$\mathrm{Mg}^{2+}$ & 15.5 & 0 \\
$\mathrm{Ca}^{2+}$ & 32.7 & 5 \\
$\mathrm{U}^{a}$ & 10.4 & 100
\end{tabular}

${ }^{a}$ Sum of all oxidative states of uranium present in solution at $\mathrm{pH} 7$. 
an increase of these groups content in PDA due to oxidation of catechol hydroxyls under treatment in the $\mathrm{HNO}_{3}$ solutions.

\subsection{The $\mathrm{U}(\mathrm{vI})$ moieties uptake from the $\mathrm{GW}$ and $\mathrm{SW}$}

The high pure PDA efficiency in the actinides uptake from the model water solutions was confirmed on the example of $\mathrm{U}(\mathrm{vI})$ uptake from simulated GW and SW. These media are highly important in terms of the ecological and possible commercial aspects even despite the fact that e.g. natural concentration of $\mathrm{U}$ in the ocean is very low ( $\sim 3.3 \mathrm{ppb}) .{ }^{31,32}$

Specifically, we have found that PDA completely removes uranium from the simulated GW with no significant retention of the background ions (Table 2). The similar high selectivity to uranium in natural SW was shown earlier for $\mathrm{Fe}_{3} \mathrm{O}_{4}$ @PDA magnetic nanoparticles. ${ }^{26}$

It should be emphasized here that during the last two decades a number of organic and inorganic ligands have been developed for extraction of uranium from GW and SW. ${ }^{33-37}$ The reported values of sorption capacity vary depending on the composition of the ligand, $\mathrm{pH}$ conditions, concentration of uranium, and presence of other metallic ions. Very often comparison between the results obtained in different laboratories is hardly possible due to large number of parameters, which might influence the result. Moreover, the uptake property depends strongly on carrying the experiments under conditions of real uranium contaminated water (field experiments) versus performing such tests under model conditions in the lab. The former case gives at least 10 times lower $Q_{\max }$ in comparison to the latter due to extremely small concentration of the analyte (ppb range in seawater) and associated with this fact additional kinetical restrictions. ${ }^{37}$ Generally, the developed polymeric sorbents have higher sorption capacity for uranium extraction (e.g., $395 \mathrm{mg} \mathrm{g}^{-1}$ phosphonic acid derivatives, up to $750 \mathrm{mg} \mathrm{g}^{-1}$ polyamidoxime $\left.{ }^{33}\right)$ in comparison to inorganic analogs (e.g., $5.6 \mathrm{mg} \mathrm{g}^{-1}$ hematite and $97.5 \mathrm{mg} \mathrm{g}^{-1}$ graphene oxide $\left.{ }^{34}\right)$. Specially developed metal organic frameworks (MOF) modified with functional groups show very impressive values of $Q_{\max }$ (up to $1684 \mathrm{mg} \mathrm{g}^{-1}$ ) at $\mathrm{pH} 4 .^{35}$ However, the same MOF do not work so well at neutral conditions of natural water $\left(188-278 \mathrm{mg} \mathrm{g}^{-1}\right.$ at pH 8 (ref. 35)). Considered as a "golden standard" for uranium extraction from SW, polyamidoxime polymer and its derivatives demonstrate high $Q_{\max }$ values in laboratory tests $(350,440$, and even $750 \mathrm{mg} \mathrm{g}^{-1}$ in synthetic uranium contaminated water ${ }^{33}$ ), while much less impressive values of $\sim 2 \mathrm{mg} \mathrm{g}^{-1}$, or $25.9 \mathrm{mg} \mathrm{g}^{-1}$ are reported for field experiments. ${ }^{33,36}$ PDA was tested mainly as a shell in polymer-inorganic composites before with the reported $Q_{\max }$ values of $384.6 \mathrm{mg} \mathrm{g}^{-1}$ (pH 7) or below. ${ }^{22}$ Based on our experiments we can conclude that previously reported $Q_{\max }$ for PDA were underestimated and that it is promising sorbent for uranium under natural water conditions with $Q_{\max }$ values approaching the best reported values for polyamidoxime and other recently developed sorbents.

Fig. 3 shows linear uptake of $U$ from the spiked SW with the adsorption step number and fast kinetics most of the retention happens during the first 2 hours followed by slow increase due to exhaust of the U(vI) concentration. Sorption capacity was not measured in these experiments but can be assumed to be like the value in the model water solution obtained for $\mathrm{pH} 6.5$ (see Fig. 2).

At the low concentration limit, isotherm shown in Fig. 3a can be best described by linear or Freundlich fit. The corresponding constants are: $K_{\mathrm{d}}=45565$ (linear fit) and $K_{\mathrm{f}}=1418 ; n=0.52$ (Freundlich fit) (Fig. S2†).

The kinetics of uranium sorption (Fig. 3b) is essentially nonlinear with the fast first adsorption process and significant reversed (i.e., desorption) process. Therefore, the kinetics is best described with the first order reversible reaction with the first rapid uptake step approximated as being instantaneous (Fig. S3†). This sorption behavior can be obviously explained from positions of the coexistence and adsorption at neutral $\mathrm{pH}$ (see above discussion of Fig. 2) of uranyl bearing species in monomer, dimer or multimer forms, ${ }^{15,21,27}$ which differ, therefore, by molecular weight and size. In line with this the rapid uptake stage begins from very fast adsorption of uranium carbonate or uranium hydroxide monomers (as more mobile species) followed by adsorption of corresponding dimers and multimers. (a)

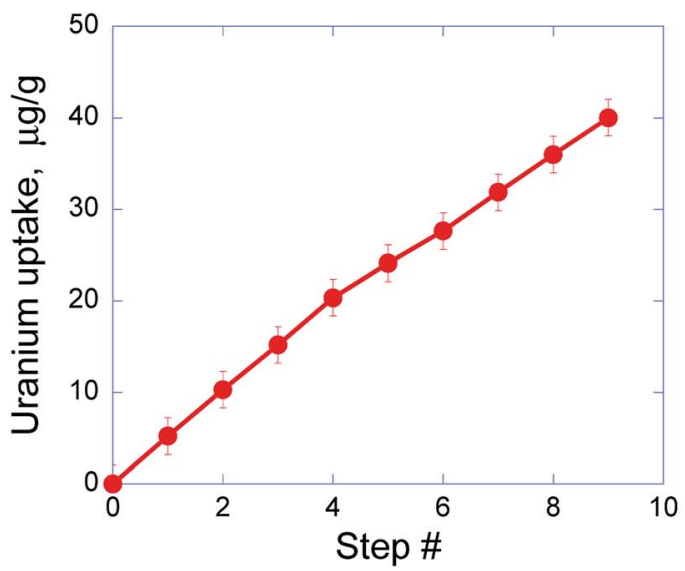

(b)

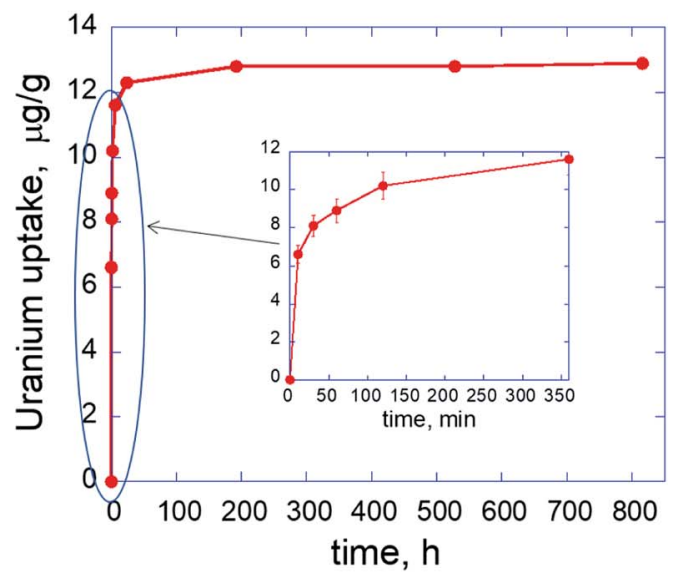

Fig. 3 Uptake of uranium by PDA from the spiked SW as a function of the adsorption step (each step lasts for $48 \mathrm{~h}$ ) (a) and kinetics of the adsorption during one-step procedure (b). Inset shows the first six hours of the adsorption experiment. 
A)

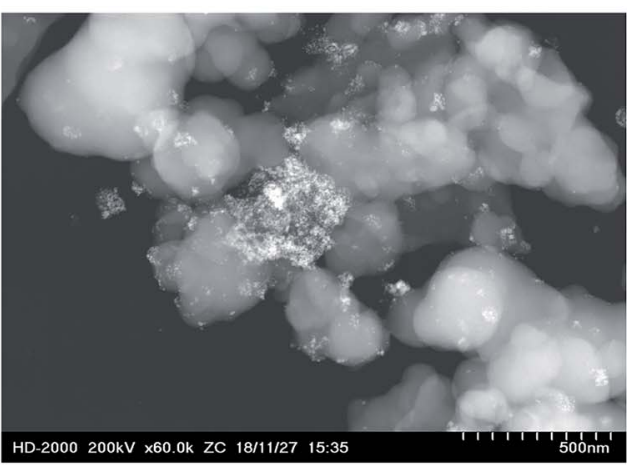

C)

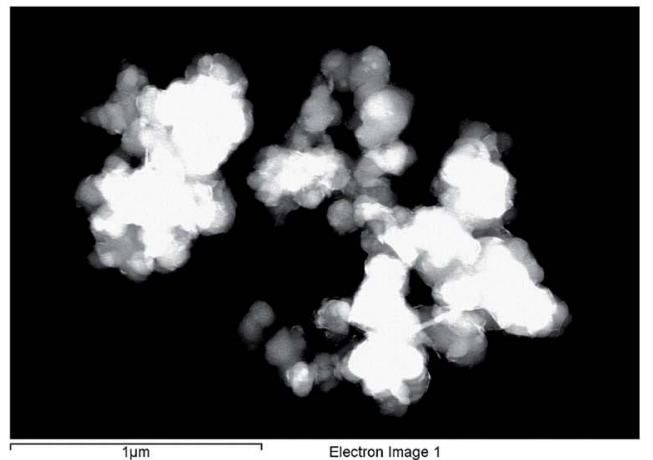

B)

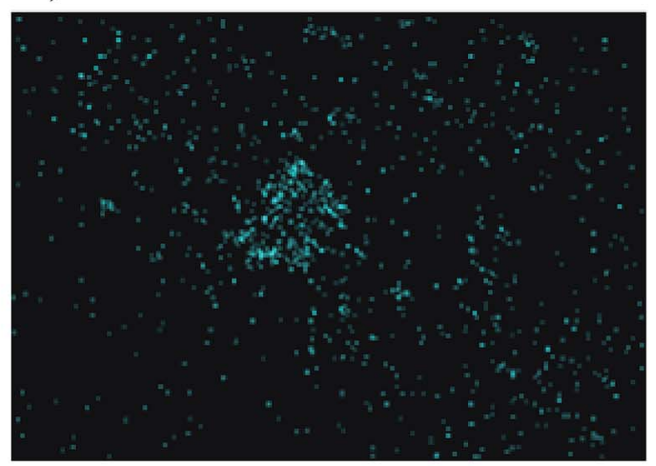

Pu La1

D)

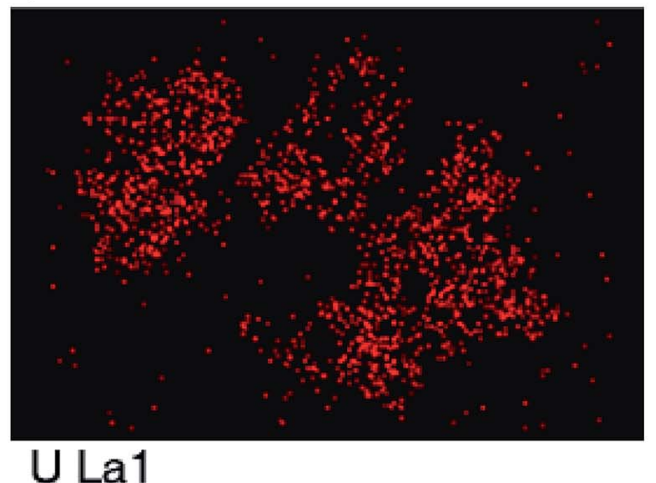

Fig. 4 (A and C) STEM image of agglomerates formed by PDA particles with ${ }^{239} \mathrm{Pu}$ containing nano-clusters (brighter color due to Z-contrast) formed during extraction of Pu based moieties from the aqueous solution at $\mathrm{pH} 7(\mathrm{~A})$ and ${ }^{238} \mathrm{U}$ radionuclides uniformly distributed on the PDA surface (C); ( $B$ and $D)$ EDS maps showing distribution of $\mathrm{Pu}(\mathrm{B})$ and $U(\mathrm{D})$ radioisotopes the same areas as shown in $(A)$ and $(C)$ correspondingly.

\subsection{Further characterization of the radionuclides uptake on the PDA sorbent}

STEM visualization. STEM images reveal aggregates of $100-$ $200 \mathrm{~nm}$ spherical PDA particles (Fig. 4A, C and S4†). Due to $Z$ contrast mode one can see the presence of high atomic number elements distributed as more or less agglomerated bright clusters on light elements background PDA particles surface. This agrees with EDS maps of the samples, which provide a solid proof of adsorption of the radionuclides moieties on the PDA surface (Fig. 4B and D). Unexpectedly EDS maps show that while $\mathrm{U}$ is distributed quite uniformly on the PDA surface (Fig. 4D), Pu is located as small spots which are irregularly and quite rarely distributed on the PDA surface (Fig. 4B). A less quantity of adsorbed Pu compared with the $\mathrm{U}$ case is also well seen in EDX spectra of these samples (Fig. S5 and S6 $\dagger$ ). This can be explained by different amount of the retained radionuclides due to different initial concentrations of the elements in water solution and different adsorption procedure (one step adsorption for Pu versus multi-step adsorption for $\mathrm{U}$ ).

FTIR consideration of the PDA after actinide moieties uptake. FTIR spectroscopy was employed to reveal details of interactions, which take place in the process of uranium and plutonium uptake. There are several structural units of PDA, which should be considered in this context including uncyclized/cyclized moieties with several types of nitrogen and oxygen functional groups. ${ }^{7-10}$ The first block to be mentioned is the parent DA unit with covalent polymerization or non-

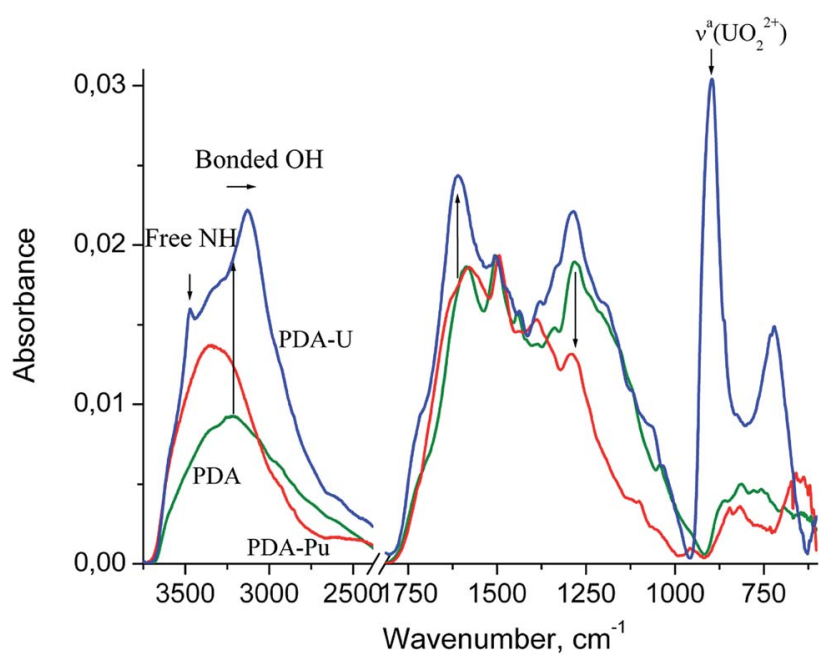

Fig. 5 ATR-FTIR spectra of PDA samples with $U$ or Pu extracted from aqueous solution at $\mathrm{pH} 4$ and $\mathrm{pH} 7$ respectively. The spectra are normalized at the maximum of the strongest band of PDA at around $1500 \mathrm{~cm}^{-1}$. The arrows indicate changes in the intensity and position of PDA bands after accumulation of radionuclides. 
covalent self-assembly contribution to PDA formation. Other important units are 5,6-dihydroxyindoline (DHIN, leucodopaminechrome) and 5,6-dihydroxyindole (DHI) produced through consecutive two-electron oxidation and intramolecular cyclization reactions of DA. Furthermore, PDA can contain quinones (dopamine quinone, 5,6-indolequinone and 2,3-dihydroindole5,6-dione) derived from above mentioned catecholamine moieties via hydrogen subtraction. In addition, pyrrole-2,3dicarboxylic acid (PDCA) and other pyrrolecarboxylic acid units can be formed from the oxidative breakdown of indole units.

Fig. 5 shows the FTIR spectra of PDA and the PDA samples are completely saturated with the adsorbed $\mathrm{U}$ or $\mathrm{Pu}$ bearing moieties separated at the end of the sorption processes from the model aqueous solutions at $\mathrm{pH} 4$ and $\mathrm{pH} 7$, respectively.

The structure of the PDA spectrum is very similar to that of parent dopamine hydrochloride (see ref. 38, SDBS no: 1654), and differs from that mainly in the broadening and merging of narrow bands. One can see a broad medium band at about $3214 \mathrm{~cm}^{-1}$ (at 3143-3371 $\mathrm{cm}^{-1}$ in DA), which can be assigned to hydrogen bonded O-H stretching vibrations, ${ }^{39-42} 1588 \mathrm{~cm}^{-1}(1579,1600$ and $1612 \mathrm{~cm}^{-1}$ assigned to aromatic $\nu_{\mathrm{C}=\mathrm{C}}^{\mathrm{a}}$ and $\left.\delta_{\mathrm{NH}_{2}}\right), 1503 \mathrm{~cm}^{-1}(1471$, 1499 and $1519 \mathrm{~cm}^{-1}$, aromatic $\nu_{\mathrm{C}=\mathrm{C}}^{\mathrm{S}}$ ), $\mathrm{NH}$ vib. in DHIN (see ref. 38, SDBS no: 1358 and 717; ref. 39-43), $1443 \mathrm{~cm}^{-1}\left(1471 \mathrm{~cm}^{-1}, \delta_{\mathrm{CH}_{2}}\right.$ vib. in DA and DHIN), $1338 \mathrm{~cm}^{-1}\left(1341\right.$ and $\left.1320 \mathrm{~cm}^{-1}, \delta_{\mathrm{C}-\mathrm{O}-\mathrm{H}}^{\mathrm{a}}\right)$ and $1282 \mathrm{~cm}^{-1}\left(1286,1260,1190,1176,1161\right.$ and $1081 \mathrm{~cm}^{-1}, \delta_{\mathrm{C}-\mathrm{O}-}^{\mathrm{s}}$ ${ }_{\mathrm{H}}, \nu_{\mathrm{C}-\mathrm{O}}$ and $\nu_{\mathrm{C}-\mathrm{C}}, \nu_{\mathrm{C}-\mathrm{C}-\mathrm{H}}^{\mathrm{a}}$. and $\left.\nu_{\mathrm{C}-\mathrm{C}-\mathrm{H}}^{\mathrm{s}}\right)$.

Strong band at about $1588 \mathrm{~cm}^{-1}$ in PDA is spreading to higher wavenumbers up to $1800 \mathrm{~cm}^{-1}$ and exhibits a shoulder at $1720 \mathrm{~cm}^{-1}$, which is characteristic of $\mathrm{C}=\mathrm{O}$ stretching vibration for carboxylic acid..$^{3940}$ Their appearance confirms the presence of pyrrolecarboxylic acid units. The above-mentioned broadening of the band is consistent with possible contribution from quinone units (o-quinones exhibit carbonyl band at about $\left.1660 \mathrm{~cm}^{-1}\right) \cdot{ }^{39}$

The most intensive band in the PDA-U spectrum (not observed in case of pure PDA) can be seen at $896 \mathrm{~cm}^{-1}$. This band can be ascribed to uranyl complex. The characteristic absorption frequency of the asymmetric vibration $\left(\nu_{3}\right)$ of free $\mathrm{UO}_{2}{ }^{2+}$ is shifted to lower wavenumbers from the free ion value of $965 \pm 1 \mathrm{~cm}^{-1}{ }^{44}$ This shift indicates coordination of the uranyl with strongly donating ligand group. ${ }^{45}$ Moreover, the band at $896 \mathrm{~cm}^{-1}$ shows a twofold enhancement of the full width at half maximum compared to the band of free $\mathrm{UO}_{2}{ }^{2+} \cdot{ }^{44}$ This can indicate variation of the existing ligand structures and stoichiometries of the complexes.

The low-frequency band at $721 \mathrm{~cm}^{-1}$ can be attributed to aquo $\left(\mathrm{H}_{2} \mathrm{O}\right)$ complexes of the uranyl cation. Except for the three fundamental modes of the free water molecules $\left(\nu_{\mathrm{OH}}^{\mathrm{a}}\right.$ and $\nu_{\mathrm{OH}}^{\mathrm{S}}$ vib. at $3550-3200 \mathrm{~cm}^{-1}$ and $\delta_{\mathrm{HOH}}$ at $\left.1630-1600 \mathrm{~cm}^{-1}\right)$, coordinated water can exhibit some libration modes in lowfrequency region $1000-200 \mathrm{~cm}^{-1} \cdot{ }^{46,47}$ The frequencies of the libration modes vary largely and depend on the bond length and orientation of the metal to water oxygen bond relative to the water molecule, the symmetry and nature of hydrogen bonds and some other geometrical factors. ${ }^{47}$ For example, the bands of medium intensity at $677,520,463$ and $421 \mathrm{~cm}^{-1}$ were ascribed to water libration and water twist in IR spectrum of the natural uranium carbonate andersonite. ${ }^{48}$ The appearance of shoulders around 1122, 1063 and $1035 \mathrm{~cm}^{-1}$ in the spectrum of PDA-U and $1101 \mathrm{~cm}^{-1}$ in the spectrum of PDA-Pu may indicate the formation of hydroxyl complexes, which exhibit the metal-OH bending mode in the region $1200-700 \mathrm{~cm}^{-1} \cdot \mathbf{. 3 9}^{39,46,49}$

In comparison to pristine PDA, PDA-U sample demonstrates a twofold enhancement of the band at $3214 \mathrm{~cm}^{-1}$ and its red shift to $3130 \mathrm{~cm}^{-1}$. The band at $1588 \mathrm{~cm}^{-1}$ shifts to $1610 \mathrm{~cm}^{-1}$ and increases distinctly in the region of $\mathrm{C}=\mathrm{O}$ stretching vibrations of the carboxylic acid groups and the quinone units. The appearance the band at $1380 \mathrm{~cm}^{-1}$ can be assigned to $\nu_{\mathrm{C}=\mathrm{O}}^{\mathrm{s}}$ vibrations of the ionized carboxyl group, which is absent in the spectrum of the unionized carboxylic acids..$^{39,40}$ In addition, the intensity of the broad band at $1282 \mathrm{~cm}^{-1}$ is enhanced mainly in the region of antisymmetric and symmetric $\mathrm{O}-\mathrm{H}$ deformation vibrations at about 1321 and $1261 \mathrm{~cm}^{-1}$. Such changes in $\mathrm{O}-\mathrm{H}, \mathrm{C}=\mathrm{O}$ bands can be induced by a change in the charge distribution on the oxygen atom when the coordinative bond formed between an oxygen donor and the uranium atom.

The PDA-U spectrum also shows sharp band at $3472 \mathrm{~cm}^{-1}$, which can be assigned to free $\mathrm{N}-\mathrm{H}$ stretching vibrations of $\mathrm{DHI}$ blocks as the indole and indoline $\mathrm{NH}$ groups show accordingly these vibrations at 3493 and $3376 \mathrm{~cm}^{-1}$ (see ref. 38, SDBS no: 717 and 1358). It is very unlikely that this band corresponds to $\nu_{\mathrm{NH}_{2}}$ and $\nu_{\mathrm{OH}}$ vibrations of DA and various catecholamine moieties. Indeed, primary amines have two bands of the $\mathrm{N}-\mathrm{H}$ asymmetric and symmetric vibrations at lower wavenumbers ${ }^{39,40}$ while $\mathrm{OH}$ groups involved in the hydrogen and coordinative bonding are revealed at lower absorption frequencies. Therefore, the $\mathrm{NH}$ groups of indole have less significant role in uranium uptake and release from initial hydrogen bonding in PDA. This reveals some different mechanism of chelation between PDA moieties and uranyl in comparison to polyamidoxime case, where simultaneous interaction of $\mathrm{UO}_{2}{ }^{2+}$ with amino groups and hydroxyls of the polymer was found to be responsible for coordination of the latter. ${ }^{37,50}$ Nevertheless, we believe that some influence of the amine groups in coordination of uranyl cannot be completely excluded.

For the sake of convenience, the repeating unit of PDA can be simplified to just 5,6-dihydroxyindole (DHI) unit. In this case, compositions of PDA-U and PDA-Pu samples can be described with following ratios:

$$
\mathrm{U}: \mathrm{DHI}=1: 5.66(\mathrm{~mol}) \text { and } \mathrm{Pu}: \mathrm{DHI}=1: 24.3(\mathrm{~mol})
$$

Importantly, PDA-U sample prepared at $\mathrm{pH}=6.5$ contains 1.7 times more of uranium in comparison to the one that obtained at $\mathrm{pH}=4$ (see Table 1 ). Therefore, formation of polynuclear uranyl complexes, which follows from the abovediscussed adsorption measurements, is quite likely. Considering linear geometry of uranyl $\mathrm{O}-\mathrm{U}-\mathrm{O}$, we can propose the following possible structures of the uranyl complexes with equatorial coordination of ligands:

The uranyl ions can form some complexes with carbonate anions in the solutions. However, the complexity of the IR spectra (Fig. 5) does not allow to identify the peaks associated with these complexes. 


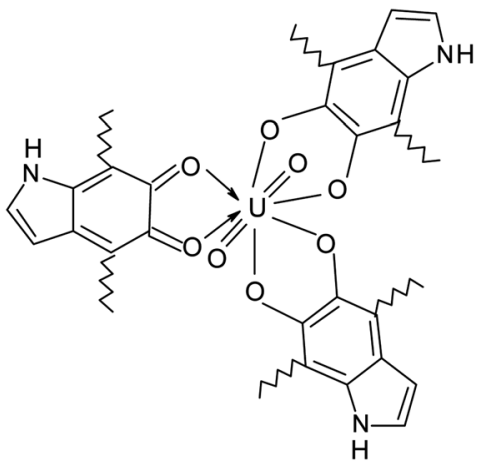

In the PDA-Pu spectrum, the weak band at $957 \mathrm{~cm}^{-1}$ can be ascribed to $\nu_{3}$ of $\mathrm{PuO}_{2}{ }^{2+}$ because the asymmetric vibration band of free ion is located at $962 \mathrm{~cm}^{-1} \cdot{ }^{44}$ Corresponding experimental $\mathrm{PuO}_{2}{ }^{+}$frequency is still unknown, although some calculations were performed. ${ }^{\mathbf{5 1} 52}$ However, considering the functional dependence of the $\mathrm{M}=\mathrm{O}$ force constant on the atomic number of a transuranium element, we can assume with a high probability that $\nu_{3}$ of $\mathrm{PuO}_{2}{ }^{+}$should be observed at lower wavenumber (close to $\nu_{3}$ of $\mathrm{NpO}_{2}^{+}$at $824 \mathrm{~cm}^{-1}$ ). ${ }^{44}$ The low intensity of the band at $817 \mathrm{~cm}^{-1}$ (PDA-Pu spectrum) and close proximity to the band $812 \mathrm{~cm}^{-1}$ (PDA spectrum) indicate absence or low content of $\mathrm{Pu}(\mathrm{v})$. As seen in Fig. 5, the intensity ratio of the bands $I\left(\nu_{3}\right.$ of $\left.\mathrm{UO}_{2}{ }^{2+}\right) / I\left(\nu_{3}\right.$ of $\left.\mathrm{PuO}_{2}{ }^{2+}\right)$ is approximately 49 , whereas the ratio [U]/ $[\mathrm{Pu}]$ is equal to 4.3. Taking into account the comparability of the band intensities of uranyl and plutonyl for solutions with similar ion concentrations, ${ }^{\mathbf{4 4}}$ it can be concluded that plutonium accumulated basically in PDA in more reduced form $\mathrm{Pu}(\mathrm{IV})$ or $\mathrm{Pu}(\mathrm{III})$.

PDA-Pu sample is also characterized by lower intensity of the band at $\sim 1282 \mathrm{~cm}^{-1}$, which is, to a large extent, related with $\delta_{\mathrm{OH}}$ and $\nu_{\mathrm{C}-\mathrm{O}}$ vibrations. This change is obviously due to the partial oxidation of the catechol $\mathrm{OH}$ groups. This is evidenced by an appreciable increase of shoulder at about $1630 \mathrm{~cm}^{-1}$, where the quinones moieties absorb. One of the possible reactions is shown below, where dihydroxyindole represents catecholamine moieties of the PDA for simplicity:

The disappearance of the $\mathrm{CH}_{2}$ scissor vibrations $\left(1443 \mathrm{~cm}^{-1}\right)$ in PDA-Pu IR spectrum also provides clear evidences for the oxidation of the DA and DHIN blocks to give in the latter case DHI block. The concert of such oxidation reactions is consistent with the drop of the absorption intensity in the region of 3070-

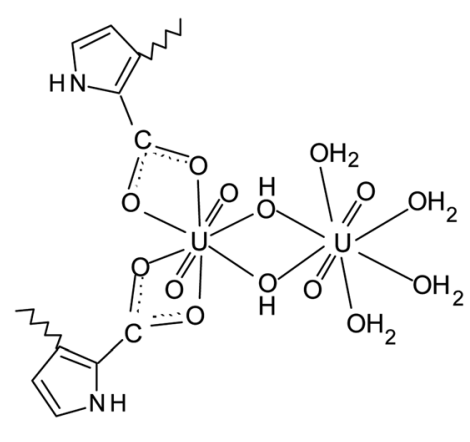

$2450 \mathrm{~cm}^{-1}$, where stretching vibrations of the strongly bounded $\mathrm{OH}$ groups and $\mathrm{C}-\mathrm{H}$ bonds typically observed.

CV characterization of the PDA samples after the radionuclides uptake. CV measurements confirm the radionuclides uptake by PDA. In particular, the "blank" pure PDA deposited on GC electrode surface displays no redox peaks within the scanning potential window (Fig. 6). On the contrary, PDA samples containing pre-adsorbed $\mathrm{U}$ or Pu species (PDA-U and PDA-Pu samples) show several well pronounced redox couples located around $\sim 0.64 \mathrm{~V} / 0.45 \mathrm{~V}, 0.15 \mathrm{~V} /-0.28 \mathrm{~V},-013(\mathrm{ox}) \mathrm{V} /$ $-0.55 \mathrm{~V}$ in case of the PDA-U sample and at around 1.21 V/1.08 $\mathrm{V}$ (shoulder), $1.03 \mathrm{~V}$ (shoulder) $/ 0.8 \mathrm{~V}$ and $-0.64 \mathrm{~V} /-0.52 \mathrm{~V}$ in case of the PDA-Pu sample (Fig. 6).

The observed positions and quantity of the redox couples differ from the previously reported ones for $\mathrm{U}$ or $\mathrm{Pu}$ in literature for bare GC electrode and various conditions. ${ }^{53-55}$ In particular, uranyl(v) nitrate in conditions close to those of this study showed only one redox couple of $\mathrm{U}(\mathrm{vI}) / \mathrm{U}(\mathrm{v})$ in cathodic region at $-0.01(\mathrm{ox}) \mathrm{V} /$ -0.25 (red) $\mathrm{V}(v s . \mathrm{Ag} / \mathrm{AgCl}){ }^{53} \mathrm{~A}$ quite similar behavior with one redox couple of $\mathrm{U}(\mathrm{vI}) / \mathrm{U}(\mathrm{v})$ at $-0.075 /-0.2 \mathrm{~V}$ (vs. $\mathrm{Ag} / \mathrm{AgCl})$ was found for uranyl(vi) perchlorate on Pt electrode in aqueous solution of $0.1 \mathrm{M}$ $\mathrm{LiClO}_{4} \cdot{ }^{56}$ However, in the more acidic medium $\left(0.1 \mathrm{M} \mathrm{HClO}_{4}\right)$ there were observed on GC electrode both a quasi-reversible redox couple $\mathrm{U}(\mathrm{vI}) / \mathrm{U}(\mathrm{v})$ at $-0.09 /-0.2 \mathrm{~V}(v s . \mathrm{Ag} / \mathrm{AgCl})$ and the irreversible anodic peak at $0.27 \mathrm{~V}$ assigned to oxidation of $\mathrm{U}(\mathrm{IV})$ to $\mathrm{U}(\mathrm{v}){ }^{57}$

In general, both uranium and plutonium electrochemistry on bare electrodes depends on $\mathrm{pH}$ and composition of the background solution. ${ }^{58}$ Specifically, in strong acidic media $\mathrm{Pu}$ multiple redox transitions $\mathrm{Pu}(\mathrm{vI}) / \mathrm{Pu}(\mathrm{v}), \mathrm{Pu}(\mathrm{vI}) / \mathrm{Pu}(\mathrm{Iv}), \mathrm{Pu}(\mathrm{v}) /$ $\mathrm{Pu}(\mathrm{Iv}), \mathrm{Pu}(\mathrm{Iv}) / \mathrm{Pu}(\mathrm{III})$ overlapping in a quite narrow potential range (with formal potentials 0.9-1.2 V vs. saturated hydrogen

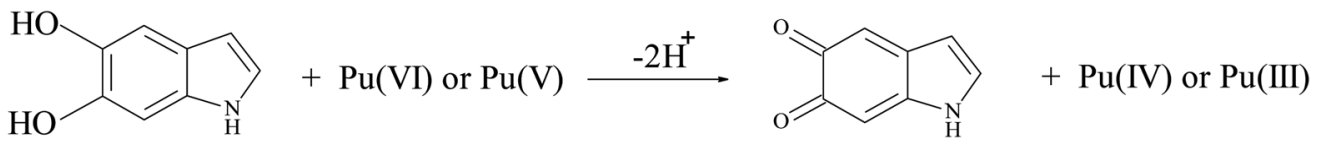




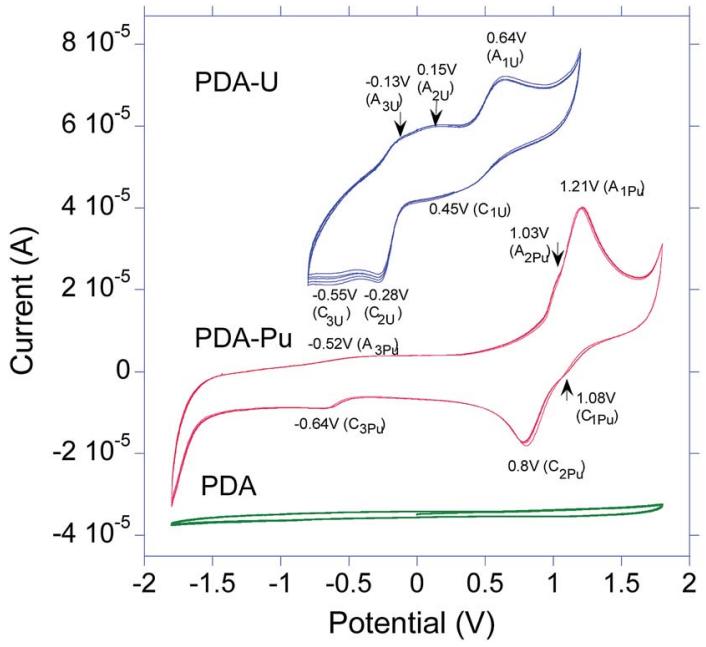

Fig. 6 Representative cyclic voltammograms recorded for PDA with pre-adsorbed $\mathrm{U}$ or Pu bearing species and pure PDA placed on the GC electrode. Background electrolytes: $0.1 \mathrm{M} \mathrm{NaClO}_{4}$ in water electrolyte (in case of PDA-U) and $0.1 \mathrm{M} \mathrm{Bu}_{4} \mathrm{NPF}_{6}$ in acetonitrile electrolyte (in case of PDA-Pu and PDA). CV curves for PDA and PDA- $U$ are shifted vertically for clarity.

electrode or about $0.68-0.98 \mathrm{~V}$ vs. different kinds of $\mathrm{Ag} / \mathrm{AgCl}$ electrodes). ${ }^{58-61}$ This overlapping can lead to the fact that on cyclic voltammograms the Pu species give wide or poorly shaped redox responses. In neutral media these processes shift to lower potentials. $^{58,60}$

The situation is quite different when the uranium or plutonium electrochemical processes run on the electrode surface covered by an adsorbent layer (e.g. graphene oxide (GO) or conducting polymer PEDOT-PSS) with or without pre-adsorbed radionuclide species. ${ }^{53-55}$ In particular, in the case of GO layer with the pre-adsorbed uranyl deposited on GC electrode the position of $\mathrm{U}(\mathrm{vI}) / \mathrm{U}(\mathrm{v})$ redox couple shifts to anodic region by around $205-250 \mathrm{mV}$ in comparison to bare GC. ${ }^{53}$ Moreover, the shape of the peaks became more complicated and additional weakly pronounced redox couple at $0.21 \mathrm{~V} / 0.13 \mathrm{~V}$ appeared that suggested both change of valence state of $U$ and altering the electronic configuration of uranyl(vi) cations due to their coordination with functional groups on the GO surface. ${ }^{53}$ Unlike the bare GC electrode case, in $1 \mathrm{M} \mathrm{H}_{2} \mathrm{SO}_{4}, \mathrm{U}(\mathrm{vI})\left(\mathrm{UO}_{2}{ }^{2+}\right)$ shows on the PEDOT-PSS/GC electrode a well-defined cathodic peak at $-0.158 \mathrm{~V}$ revealing its reduction to $\mathrm{U}(\mathrm{Iv})$ through the $e c$ (electron transfer-chemical step) stage including formation of $\mathrm{U}(\mathrm{v})\left(\mathrm{UO}_{2}{ }^{+}\right)$ and its very fast disproportionation into $\mathrm{UO}_{2}{ }^{2+}$ and $\mathrm{U}(\mathrm{Iv}) .^{55}$

While to our knowledge there is no published information on electrochemistry of highest valence state of Pu on adsorbent coated electrodes, it is found that the GO or PEDOT:PSS layers on GC showed enhanced electrocatalytic activity towards $\mathrm{Pu}(\mathrm{Iv}) /$ $\mathrm{Pu}(\mathrm{III})$ redox couple and significantly decreased the cathodic and anodic peak potentials in acidic media $\left(1 \mathrm{M} \mathrm{H}_{2} \mathrm{SO}_{4}\right) .^{52,54,55} \mathrm{In}$ particular, due to the GO influence this redox couple shifted from $0.666 \mathrm{~V} / 0.092 \mathrm{~V}$ to $0.605 \mathrm{~V} / 0.398 \mathrm{~V}$ (ref. 54) while due to the PEDOT:PSS influence the couple shifted from $0.674 \mathrm{~V} / 0.132 \mathrm{~V}$ on the bare GC electrode to $0.540 \mathrm{~V} / 0.496 \mathrm{~V}^{62}$
If compare the known electrochemical transitions of $\mathrm{U}$ and $\mathrm{Pu}$ bearing species in different valence states ${ }^{53-62}$ on bare and coated electrodes with positions of the redox couples of the PDA-U and PDA-Pu samples (Fig. 6) one can see that in the case of PDA the shifts of these transitions along the potential axis and, therefore, specific interactions of PDA with the actinides species are significantly stronger than in the cases of GO or PEDOT:PSS. This electrochemical specificity of pure PDA in interactions with the radionuclides matches well with the discussed above high adsorption ability of PDA and formation of uranium and plutonium complexes. Interaction with PDA and resulting oxidation of PDA moieties by actinides in highest oxidation states (VI) causing appearance of reduced forms of the actinides in PDA. Such redox processes lead obviously to the existence in the PDA-U and PDA-Pu samples of $U$ and Pu in different valence states (VI, V, IV, III), which are revealed in the poorly resolved three redox couples encompassing in fact the redox transitions between these states in their cyclic voltammograms. An additional input in shape and quantity of these couples can be probably made by involvement in the electrochemical reactions of the actinide's complexes with some PDA moieties (e.g. hydroxyl or amino groups). However, to more precisely identify these redox couples a detailed characterization in a separate electrochemical work is needed.

\section{Conclusions}

As a result of our study the pure PDA polymer has been identified as a material with extremely high sorption capacity that is capable of concentrating soluble uranium and plutonium bearing species from GW and SW at weakly acidic and nearneutral pH. Its binding ability for uranium is realized probably due to formation of uranyl complexes with catechol- and amino- and other functional groups. This effect is synergistically enhanced especially at neutral $\mathrm{pH}$ by involvement in such complexation process of uranyl bearing species in monomer, dimer or multimer forms.

In particular, the uptake of uranium bearing species starts as a rapid uptake step on the order of minutes followed by a slow equilibration that can be approximated as a first-order reversible reaction. The strong interaction between $\mathrm{U}(\mathrm{vI})$ and PDA was demonstrated by the high sorption capacity $480 \mathrm{mgU} / \mathrm{gPDA}$, even in complex media such as e.g. SW. The high uptake of plutonium bearing species can be explained not only by the same reasons but also through the partial oxidation of the catechol $\mathrm{OH}$ groups by $\mathrm{Pu}(\mathrm{v} / \mathrm{vI})$ accompanied with appearance of $\mathrm{Pu}(\mathrm{Iv})$ bearing species.

The results of this study strongly confirm that the pure PDA polymer has a significant potential to be used for removal of the radionuclides from different contaminated waters (e.g. GW, seawater), for the mining of uranium from SW and moreover for development of new radioanalytical methods. Nevertheless, the known variability of the PDA composition suggest that further characterization is still necessary to assess its full potential. 


\section{Conflicts of interest}

There are no conflicts to declare.

\section{Acknowledgements}

The authors are grateful to Ms. Amruta Pujari for her help with uranium uptake experiments. This work was partly funded under a NATO Science for Peace and Security Program, G5094 grant entitled: Reliable nuclear materials identification technology from spectrometry data. Research in this manuscript dealing with plutonium was funded by the Office of Basic Energy Sciences of the U.S. Department of Energy as part of the Heavy Element Chemistry Program (DE-SC0010355) and by the Department of Energy National Nuclear Security Administration Stewardship Science Academic Alliances (\#DE-NA-0002920). Dr Kamila Kołacińska would like to acknowledge her support from the Fulbright Scholars Program.

\section{References}

1 M. Deng, H. Zhao, S. Zhang, C. Tian, D. Zhang, P. Du, C. Liu, H. Cao and H. Li, J. Mol. Catal. B: Enzym., 1970, 112, 15-24.

2 M. F. Mineyeva, D. Tummler, E. A. Kuznetsova, A. E. Vasiliev and K. S. Rayevsky, Ann. Ist. Super. Sanita, 1982, 18, 45-48.

3 E. Herlinger, R. F. Jameson and W. Linert, J. Chem. Soc., Perkin Trans. 2, 1995, 259-263.

4 K. Liu, W. Z. Wei, J.-X. Zeng, X.-Y. Liu and Y.-P. Gao, Anal. Bioanal. Chem., 2006, 385, 724-729.

5 H. Lee, S. M. Dellatore, W. M. Miller and P. B. Messersmith, Science, 2007, 3180, 426-430.

6 J. H. Ryu, P. B. Messersmith and H. Lee, ACS Appl. Mater. Interfaces, 2018, 10, 7523-7540.

7 Y. Liu, K. Ai and L. Lu, Chem. Rev., 2014, 114, 5057-5115.

8 M. d'Ischia, A. Napolitano, V. Ball, C.-T. Chen and M. J. Buehler, Acc. Chem. Res., 2014, 47, 3541-3550.

9 S. Hong, Y. S. Na, S. Choi, I. T. Song, W. Y. Kim and H. Lee, Adv. Funct. Mater., 2012, 22, 4711-4717.

10 J. Liebscher, R. Mrowczynski, H. A. Scheidt, C. Filip, N. D. Hadade, R. Turcu, A. Bende and S. Beck, Langmuir, 2013, 29, 10539-10548.

11 J. Park, T. F. Brust, H. J. Lee, S. C. Lee, V. J. Watts and Y. Yeo, ACS Nano, 2014, 8, 3347-3356.

12 R. Luo, L. Tang, J. Wang, Y. Zhao, Q. Tu, Y. Weng, R. Shen and N. Huang, Colloids Surf., B, 2013, 106, 66-73.

13 M. Lee, J. Rho, D. E. Lee, S. Hong, S. J. Choi, P. B. Messersmith and H. Lee, ChemPlusChem, 2012, 77, 987-990.

14 Z. Iqbal, S. Alsudir, M. Miah and E. P. C. Lai, Electrophoresis, 2011, 32, 2181-2187.

15 K. Zhu, S. Lu, Y. Gao, R. Zhang, X. Tan and C. Changlun, Appl. Surf. Sci., 2017, 396, 1726-1735.

16 N. Farnad, K. Farhadi and N. H. Voelcker, Water, Air, Soil Pollut., 2012, 223, 3535-3544.

17 C. Lim, J. Huang, S. Kim, H. Lee, H. Zeng and D. S. Hwang, Angew. Chem., Int. Ed., 2016, 55, 3342-3346.
18 X. Zhang, X. Jia, G. Zhang, J. Hu, W. Sheng, Z. Ma, J. Lu and Z. Liu, Appl. Surf. Sci., 2014, 314, 166-173.

19 H. Gao, Y. Sun, J. Zhou, R. Xu and H. Duan, ACS Appl. Mater. Interfaces, 2013, 5, 425-432.

20 C. M. Hui, J. Pietrasik, M. Schmitt, C. Mahoney, J. Choi, M. R. Bockstaller and K. Matyjaszewski, Chem. Mater., 2014, 26, 745-762.

21 L. Bai, S. Duan, W. Jiang, M. Liu, S. Wang, M. Sang, X. Gong, J. Li and S. Xuan, Appl. Surf. Sci., 2017, 426, 1121-1132.

22 J. Zhu, Q. Liu, J. Liu, R. Chen, H. Zhang, M. Zhang, P. Liu, R. Li and J. Wang, J. Taiwan Inst. Chem. Eng., 2018, 91, 266-273.

23 D. Langmuir, Aqueous Environmental, Geochemistry Prentice Hall, NJ, 1997.

24 J. Y. Zeng, H. Zhang, Y. Sui, N. Hu, D. Ding, F. Wang, J. H. Xue and Y. D. Wang, Ind. Eng. Chem. Res., 2017, 56, 5021-5032.

25 J. Bidwell and S. Spotte, Artificial Seawaters: Formulas and Methods, Jones and Barlett, Boston, 1985.

26 F. Wu, N. Pu, G. Ye, T. Sun, Z. Wang, Y. Song, W. Wang, X. Huo, Y. Lu and J. Chen, Environ. Sci. Technol., 2017, 51, 4606-4614.

27 W. Dong and J. Wan, Environ. Sci. Technol., 2014, 48, 65696577.

28 B. A. Powell, A. B. Kersting, M. Zavarin and P. Zhao, Development of a Composite Non-Electrostatic Surface Complexation Model Describing Plutonium Sorption to Aluminosilicates, U.S. Department of Energy by Lawrence Livermore National Laboratory, report under contract DEAC52-07NA27344, 2011, DOI: 10.2172/1019063.

29 A. Zhang, T. Asakura and G. Uchiyama, React. Funct. Polym., 2003, 57, 67-76.

30 T. Wen, X. Wang, J. Wang, Z. Chen, J. Li, J. Hu, T. Hayat, A. Alsaedi, B. Grambow and X. Wang, Inorg. Chem. Front., 2016, 3, 1227-1235.

31 H. J. Schenk, L. Astheimer, E. G. Witte and K. Schwochau, Sep. Sci. Technol., 1982, 17, 1293-1308.

32 F. Wang, H. Li, Q. Liu, Z. Li, R. Li, H. Zhang, L. Liu, G. A. Emelchenko and J. Wang, Sci. Rep., 2016, 6, 19367.

33 M. M. Aly and M. F. Hamza, J. Dispersion Sci. Technol., 2013, 34, 182-213.

34 Y. Zou, P. Wang, W. Yao, X. Wang, Y. Liu, D. Yang, L. Wang, J. Hou, A. Alsaedi, T. Hayat and X. Wang, Chem. Eng. J., 2017, 330, 573-584.

35 W. Yang, Q. Pan, S. Song and H. Zhang, Inorg. Chem. Front., 2019, 6, 1924-1937.

36 L. Chen, Z. Bai, L. Zhu, L. Zhang, Y. Cai, Y. Li, W. Liu, Y. Wang, L. Chen, J. Diwu, J. Wang, Z. Chai and S. Wang, ACS Appl. Mater. Interfaces, 2017, 9, 32446-32451.

37 B. F. Parker, Z. Zhang, L. Rao and J. Arnold, Dalton Trans., 2018, 47, 639-644.

38 Spectral Database for Organic Compounds SDBS, National Institute of Advanced Industrial Science and Technology (AIST), Japan [Online], https://sdbs.db.aist.go.jp/sdbs/cgibin/cre_index.cgi. 
39 G. Socrates, Infrared and Raman characteristic group frequencies: tables and charts, John Wiley \& Sons, Chichester, 2001.

40 L. J. Bellamy, The infra-red spectra of complex molecules, Chapman and Hall, London, 1975.

41 S. Gunasekaran, R. T. Kumar and S. Ponnusamy, Indian J. Pure Appl. Phys., 2007, 45, 884-892.

42 F. Yu, S. Chen, Y. Chen, H. Li, L. Yang, Y. Chen and Y. Yin, J. Mol. Struct., 2010, 982, 152-161.

43 D. G. O'Sullivan, J. Chem. Soc., 1960, 3278-3284.

44 L. H. Jones and R. A. Penneman, J. Chem. Phys., 1953, 21, 542-544.

45 S. Fortier and T. W. Hayton, Coord. Chem. Rev., 2010, 254, 197-214.

46 K. Nakamoto, Infrared and Raman Spectra of Inorganic and Coordination Compounds, John Wiley \& Sons, New York, Chichester, Brisbane, Toronto, Singapore, 1986.

47 V. P. Tayal, B. K. Srivastava, D. P. Khandelwal and H. D. Bist, Appl. Spectrosc. Rev., 1980, 16, 43-134.

48 N. Kalashnyk, D. L. Perry, F. Massuyeau and E. Faulques, J. Phys. Chem. C, 2018, 122, 7410-7420.

49 H. P. Emerson and B. A. Powell, Radiochim. Acta, 2015, 103, 553-563.

50 D. S. Bolotin, N. A. Bokach and V. Yu. Kukushkin, Coord. Chem. Rev., 2016, 313, 62-93.

51 J. Hay, R. L. Martin and G. Schreckenbach, J. Phys. Chem. A, 2000, 104, 6259-6270.
52 G. A. Shamov and G. Schreckenbach, J. Phys. Chem. A, 2005, 109, 10961-10974.

53 V. N. Bliznyuk, N. A. Conroy, Y. Xie, R. Podila, A. M. Rao and B. A. Powell, Phys. Chem. Chem. Phys., 2018, 20, 1752-1760.

54 S. K. Guin, A. S. Ambolikar and J. V. Kamat, RSC Adv., 2015, 5, 59437-59446.

55 R. Agarwal, M. K. Sharma, K. Jayachandran, J. S. Gamare, D. M. Noronha and K. V. Lohithakshan, Anal. Chem., 2018, 90, 10187-10195.

56 K. Mizuguchi, Y.-Y. Park and H. Tomiyasu, J. Nucl. Sci. Technol., 1993, 30, 542-548.

57 Y. Suzuki, T. Nankawa, T. Ozaki, T. Ohnuki, A. J. Francis, Y. Enokida and I. Yamamoto, J. Nucl. Sci. Technol., 2007, 44, 1227-1232.

58 D. L. Clark, S. S. Hecker, G. D. Jarvinen and M. P. Neu, in The Chemistry of the Actinides and Transactinide Elements, ed. L. R. Morss, N. M. Edelstein and J. Fuger, Springer, Dordrecht, 2006, pp. 813-1264.

59 S. Kihara, Z. Yoshida, H. Aoyagi, K. Maeda, O. Shirai, Y. Kitatsuji and Y. Yoshida, Pure Appl. Chem., 1999, 71, 1771-1807.

60 B. Allard, H. Kipatsi, J. O. Liljenzin and J. Inorg, Nucl. Chem., 1980, 42, 1015-1027.

61 A. Fallet, N. Larabi-Gruet, S. Jakab-Costenoble and P. Moisy, J. Radioanal. Nucl. Chem., 2016, 308, 587-598.

62 R. Agarwal and M. K. Sharma, Electrochim. Acta, 2017, 224, 496-502. 